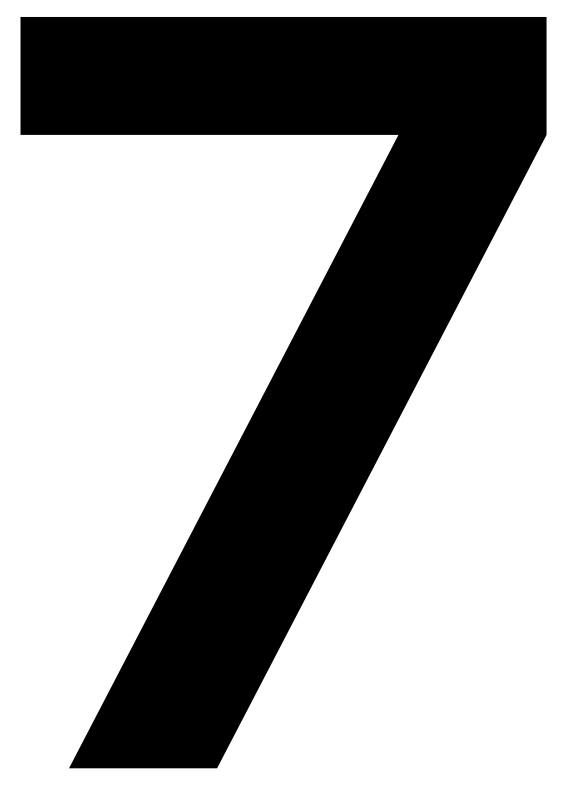

Publishing a Research Video:

Uploading to the Media Archive Martin Grödl, Moritz ResI 
This guide will show you how to publish your Research Video project on the ZHdK Media Archive.

Please note: This guide contains some basic actions that are dependent on your operating system, such as renaming files, extracting archives, and editing text files. The guide is written from the perspective of a macOS user. Please adapt accordingly if you are using a different OS. 
Before you can start you have to get your personal login by sending an e-mail to research.video@zhdk.ch. Please specify:

O Name of the project

$\circ$ First and last name

$\circ$ E-mail address

$\circ$ Date of expiration of required access

You will receive an e-mail as soon as your login has been created.

\section{Step-by-Step Guide}

Step 1

Export your RV Project

01 In Research Video, select the Project button.

02 Select Export in the Project pop-up.

03 Select OK when you are asked if you want to export an archive of your project.

01 Right-click the downloaded .rv file and select Rename.

02 Change the file extension from .rv to .zip. If prompted, confirm that you want to change the file's extension.

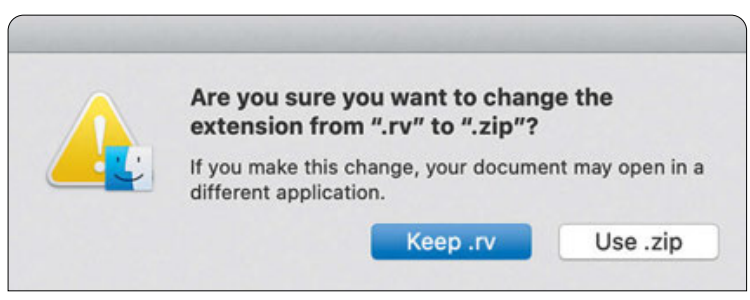




\section{Step 3}

\section{Extract ZIP file}

This will give you two files:

o video.m4v, which is the video file used in your project;

$\circ$ project.json, which contains all the annotations you made in Research Video.

Both of these files will be uploaded to the Media Archive in the following steps.

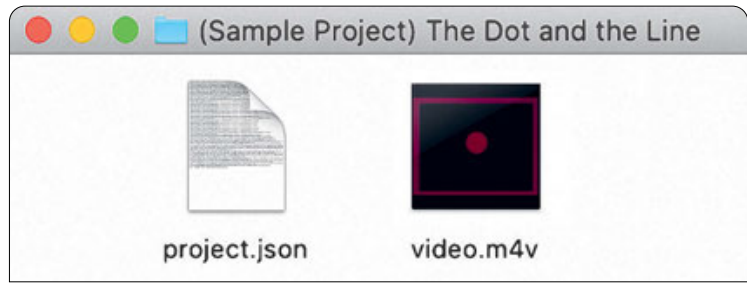

\section{Step 4}

Upload video to Media Archive

01 Log in to the Media Archive at https://medienarchiv.zhdk.ch.

02 Select Upload Media.

03 Upload video.m4v from the previous step and wait until the upload is finished.

04 Select Complete media entries.

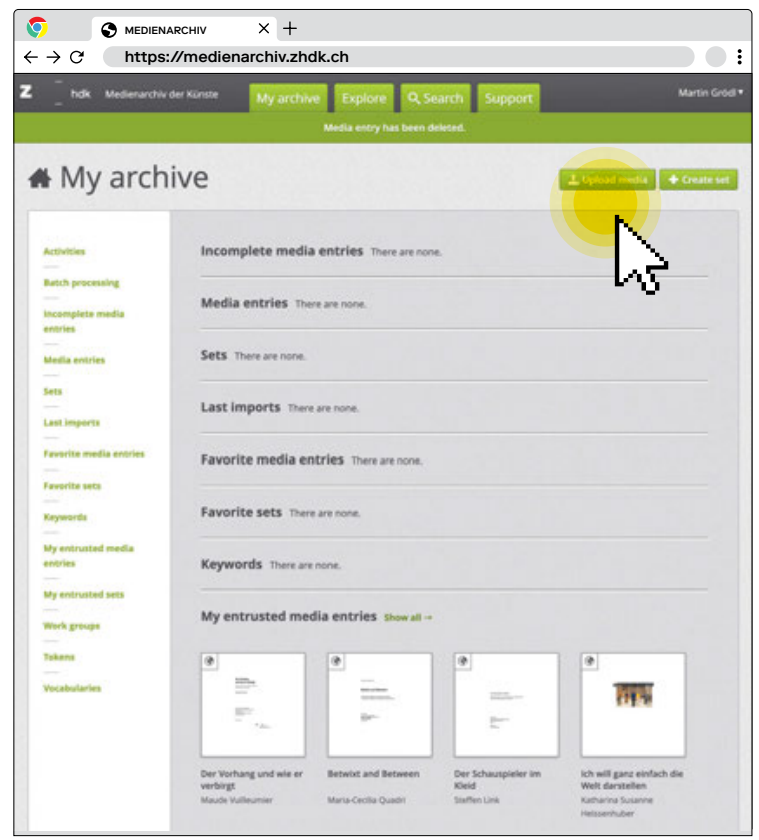


01 Select the incomplete media entry video.m4v.

02 Select the Edit metadata button, the small pencil icon on the top right corner.

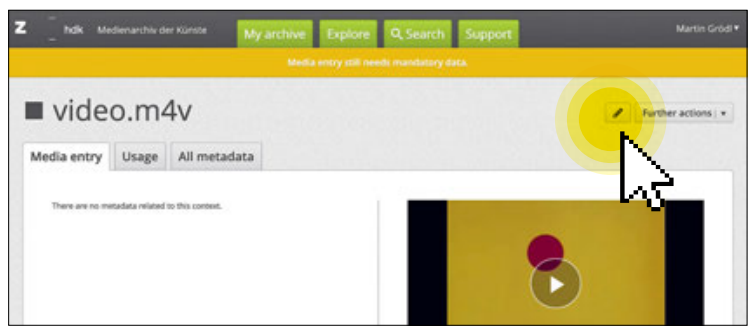

03 Add the required information:

$\circ$ a meaningful title

$\circ$ the copyright holder

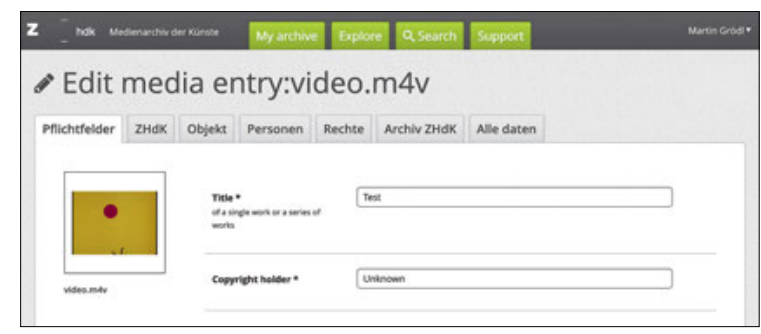

04 Select Alle Daten and then RESEARCH VIDEO.

05 Paste the contents of the project.json file that you extracted previously into the box Research Video annotations:

$\bigcirc$ Right-click the project.json file to open it.

$\circ$ Select Edit $\rightarrow$ Select All, then select Edit $\rightarrow$ Copy to copy all the.$j s o n$ data.

O Back in the Media Archive, select the Research Video annotations box, then right-click and select Paste. The .json data should appear in the box.

06 Save the changes.

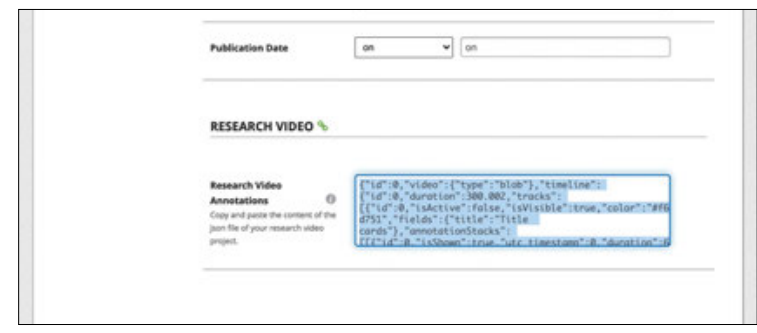




\section{Step 6}

Set permissions (optional)

This step is necessary if you want to share your Research Video project with people outside of the Media Archive.

01 On the Media entry page, select Permissions.

02 Select Edit.

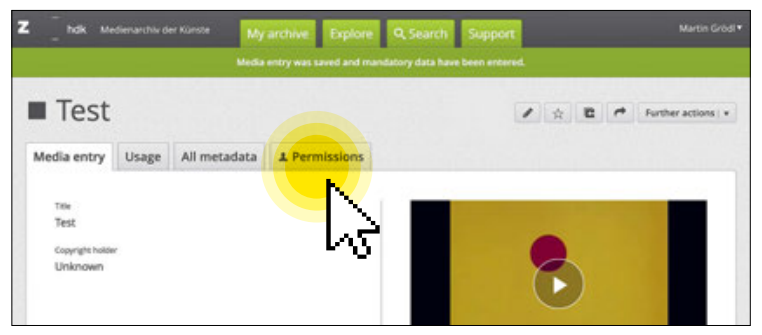

03 Select the View checkbox in the row Public/Internet.

04 In the same row, select the checkbox Download original \& browse PDF.

05 Save the changes.

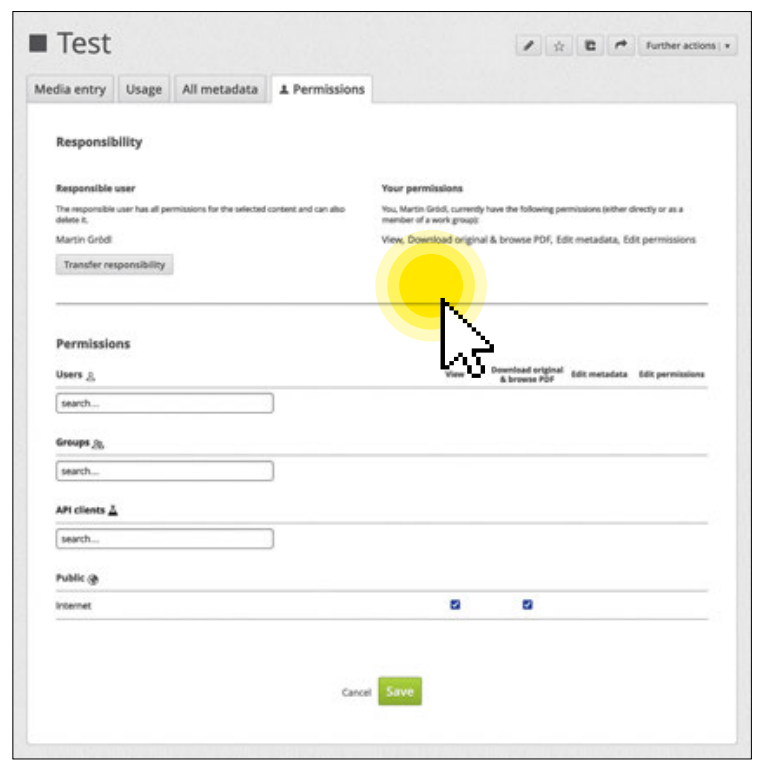




\section{Step 7}

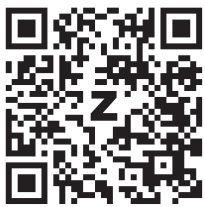

\section{Get a shareable URL}

Your upload is now complete, but you still need to generate a unique URL so you can view and share your Research Video.

01 First copy the URL of your Media Archive entry.

02 Go to https://rv.zhdk.ch/madek-link, paste your URL and select Get RV link.

03 A Research Video URL will be generated. Select the Copy button or copy it manually.

04 This is the link to your Research Video published on the ZHDK Media Archive! If you set the permissions in Step 6, anybody with this link can view your published Research Video.
Step 8

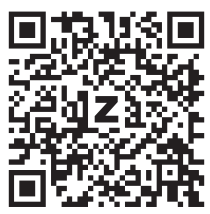

Add URL to Media Archive entry (optional)

It is good practice to store the Research Video URL with the associated Media Archive entry.

01 Back at https://medienarchiv.zhdk.ch select the Edit button in your Media entry.

02 Select Objekt and scroll down to Internet Links (URL).

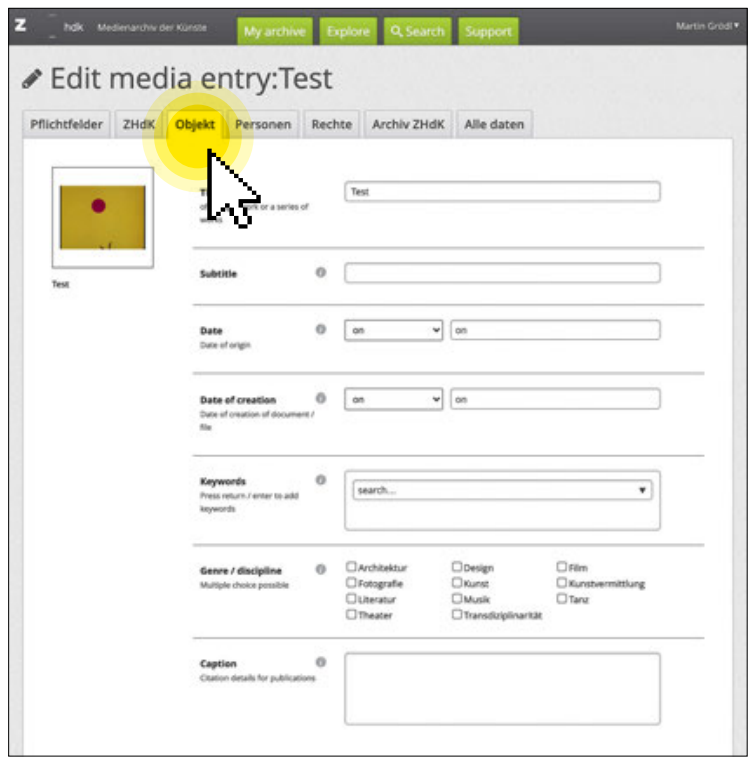


03 Enter a link identifier such as "Research Video Link:" and paste the URL.

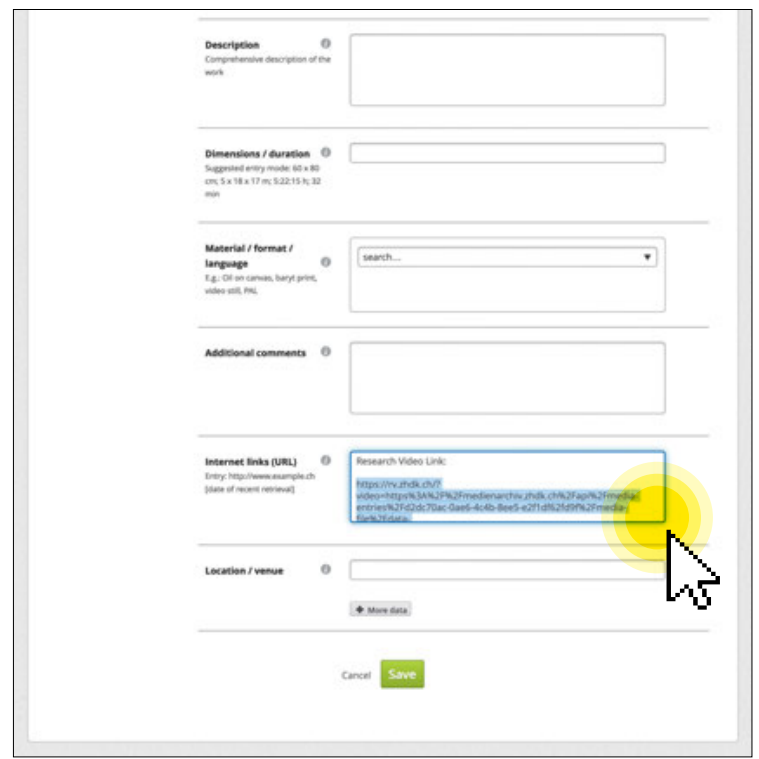

04 Save the changes.

The URL will now appear on your Media entry page and links directly to the Research Video application.

This process will take up to one hour. After that the researcher can share his or her Research Video project by simply sending the URL. 
\%

6.

6

.

s.t.

r.

6.t.

ton

r.

$x_{2}, 7,2$

tisto

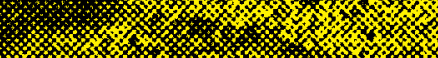

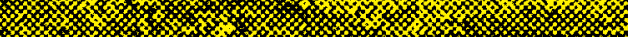

$\$$
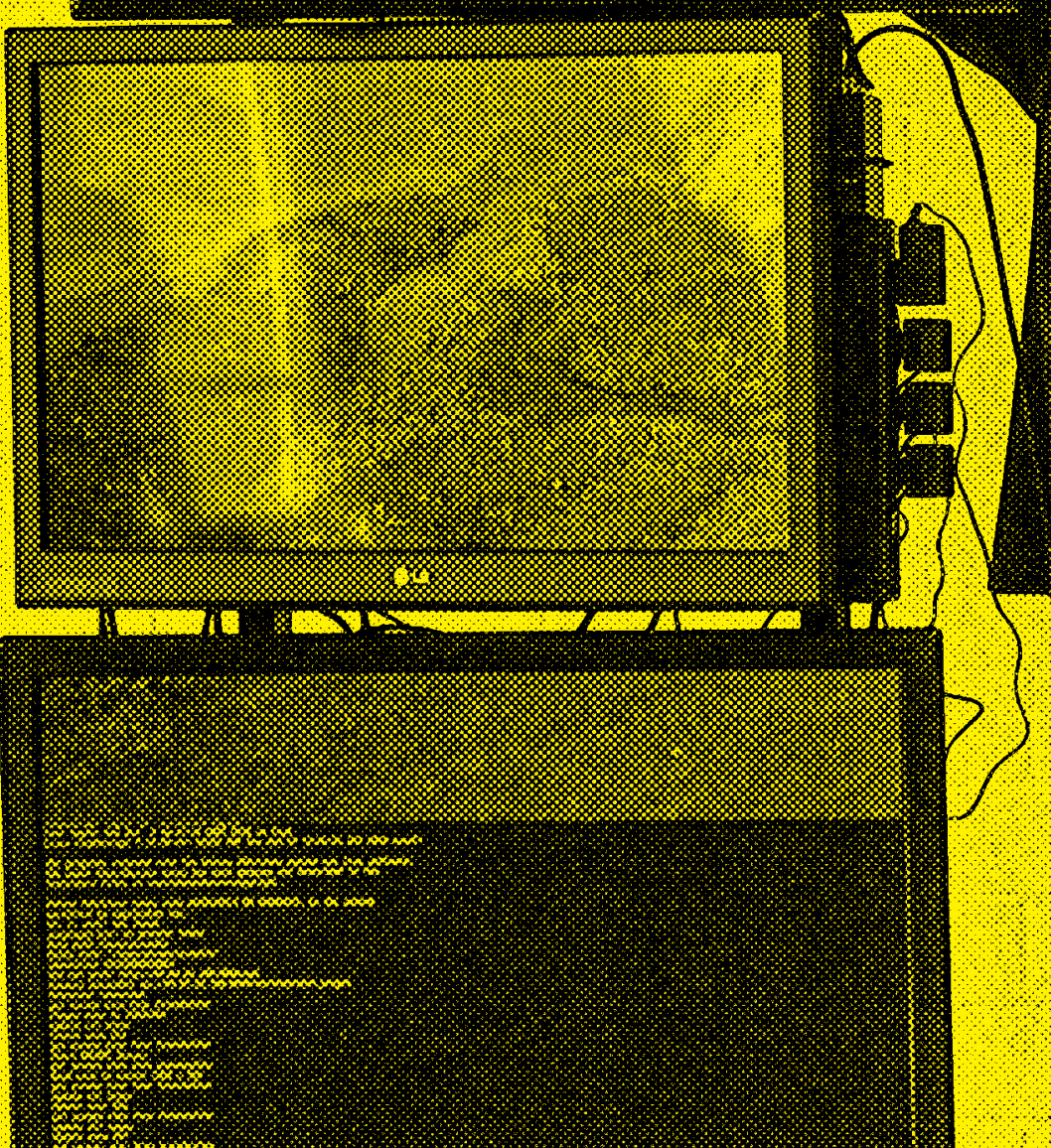

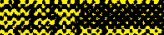

280
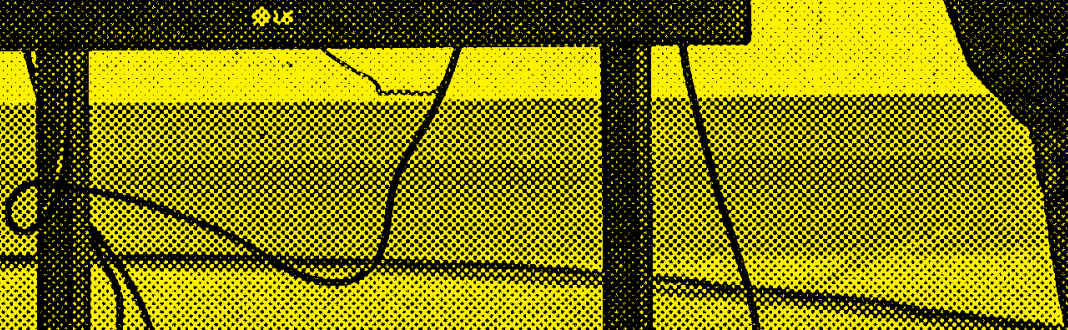
\%

w

.

(6)

4.t.

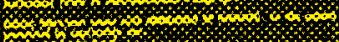

m.

,

of

(n)

.

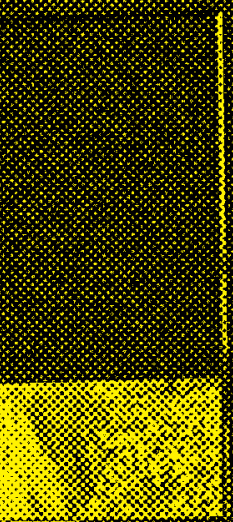

34

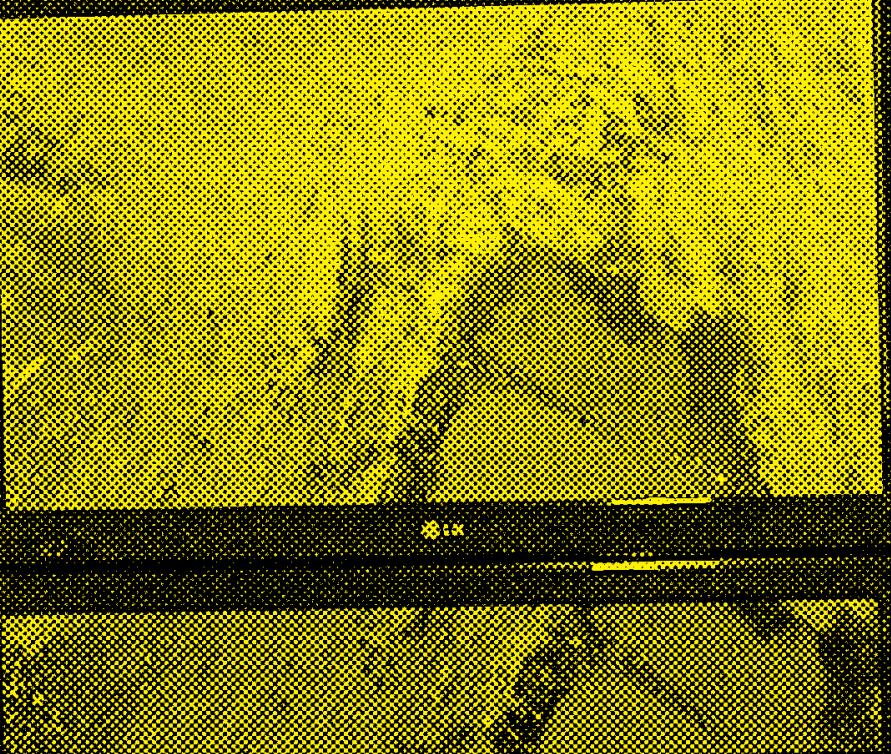

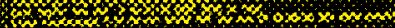

6

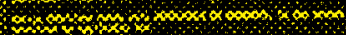

s.m.

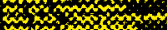

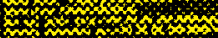

monstom

and

(1)

sis

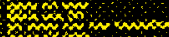

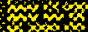

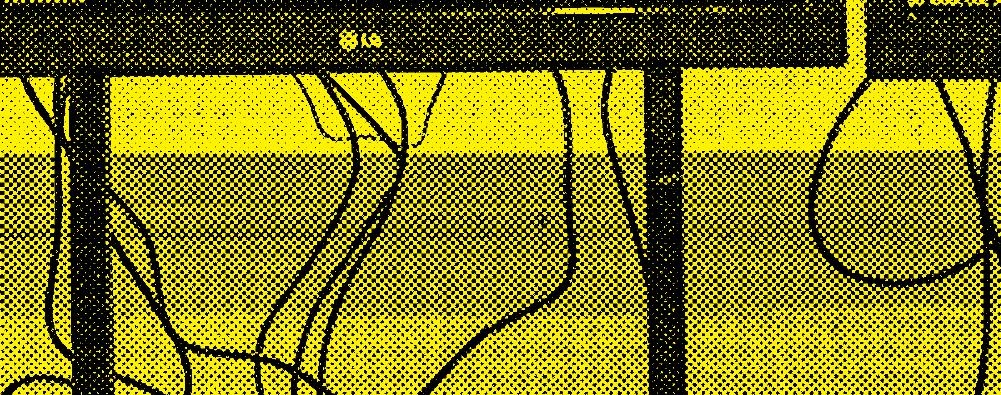

